\title{
A DIFFRACTIVE EXPLORATION OF AFFECT: LEARNING, RESEARCH AND TEACHING IN OBSTETRICS
}

\author{
V. Mitchell \\ PhD student \\ Department of Physiotherapy \\ University of the Western Cape \\ Bellville, South Africa \\ e-mail: veronicaannmitchell@gmail.com
}

\section{ABSTRACT}

Instances of abuse, neglect and disrespect to women in labour are not uncommon in South Africa's public health birthing facilities. These social injustices are surrounded by a pervasive silence that confronts undergraduate medical students in their first practical obstetrics rotation.

In this article I draw on affect theory to explore how students engage with these unjust practices. Through a diffractive analysis I question how drawings can be used to elicit affect as a pedagogic device towards developing a socially just pedagogy in obstetrics. In this ethics-approved study I address three aspects of student learning. Firstly, the ways in which the medical curriculum appears to obfuscate affect. Secondly, how affect is entangled in student learning, complicating responses to unjust practices. Thirdly, how drawings as data-in-the-making have elicited students' affective responses to confront difficult curriculum encounters. This visual methodology is thus opening in/determinate educational spaces for activism against unjust practices.

Keywords: affect, socially just pedagogy, obstetrics, medical education, student learning, diffraction, drawings

\section{INTRODUCTION}

Are we avoiding confrontations with injustices in our efforts to meet professional accreditation needs and aspirational graduate profiles? This question triggered my interest in educational practices which focus on the achievement of knowledge and skills; at times at the expense of other issues impacting on student learning. The spark for this article and related research study was my experience of listening to and reading about medical students' experiences in the public health birthing facilities in the Western Cape, South Africa. The prevalence of abuse, neglect and disrespect of women in labour by health 'care' providers was astounding. Students' anecdotal accounts were consistent with past (Jewkes, Abrahams and Mvo 1998) and recent findings (Chadwick, Cooper and Harries 2014; Kruger and Schoombee 2010). For instance, students frequently witness the screaming of abuse at non-compliant women. This continues to be troubling for me as a teacher and for the ongoing process of students' becoming, of which 
'there is already more to come’ (Massumi 2011, 6).

Rather than pathologising these 'other issues' a turn to affect offers an affirmative and productive response (Zembylas 2006). Jansen’s (2009) insights into educational practices across racial conflicts suggest that teachers ought to engage and locate themselves in troubling spaces such as developing conversations around prevailing injustices. Zembylas (2006, 314) explains how the witnessing of injustices can be used by educators to open up classroom dialogues that have the potential to be 'a fundamentally powerful affective experience' to promote social justice. However, such dialogues are challenging for educators and students, provoking varying levels of discomfort. This approach is understandably avoided by educators who choose to maintain a status quo. In this article I put forward an affective pedagogical approach that has transformative possibilities for students (and educators). It can foster students' activism in their becoming advocates for change.

In order to develop a praxis towards a socially just pedagogy, I explore students’ learning in their initial rotation of practical obstetrics, a time when students feel they are becoming real doctors - a threshold moment considered by both educators and students as a rite of passage. Yet this vital pedagogical space contains unexpected and hidden challenges.

Affect theory opens up a way for theorizing students' troubled curricular experiences. It offers a fresh approach, known as the affective turn (Clough 2007). In what follows I describe a research project (linked to my teaching) in which affect is foregrounded with and through drawings. My primary question through this article asks how drawings can elicit affect as a pedagogic device towards developing a socially just pedagogy in obstetrics.

This article comprises three sections that contribute towards addressing the lead question. The first part introduces the concept of affect and how the curriculum in obstetrics appears to obfuscate affect through its epistemological dominance. The second section describes how affect matters in obstetrics learning. I explain Barad's (2007) concept of diffraction in terms of the entanglements and intra-actions that effect affect. Diffraction as a methodology opens up new possibilities from which I explore the effects of differences in which matter matters (Barad 2007). This perspective moves beyond reflexivity, which for Barad (2007) is about mirroring sameness, and conventional coding (MacLure 2013). In the third section I describe how drawings-in-the-making are productive for eliciting affect in order to enable students to learn and respond to social injustices in obstetrics. Drawings offer a visual tool to compliment teaching, and research interviews and focus group discussions, Limitations of this study are discussed before concluding. 


\section{TURNING TO AFFECT}

Theorizing with and through affect can be an enabler for change. The usefulness to education and pedagogy is becoming increasingly evident (Hickey-Moody and Page 2015; Zembylas 2006). In this article I use a Deleuzian understanding of affect, an affirmative approach that moves away from representation with a focus rather on the intensities and capabilities that power the body to move or be moved (Colebrook 2002).

Affect is more than emotion. It is 'our power to affect the world around us and our power to be affected by it, along with the relationship between these two powers' (Hardt in Clough 2007, ix). It is a dynamic opening up to possibilities that can effectuate change. This transition is explained by Massumi (in Zournazi 2002, 212) as a 'passing of a threshold, seen from the point of view of the change in capacity'. Thus, '[w]hen you affect something, you are at the same time opening yourself up to being affected in turn, and in a slightly different way than you might have been the moment before. You have made a transition, however slight.'

Massumi (1987) defines affect as 'a prepersonal intensity corresponding to the passage from one experiential state of the body to another and implying an augmentation or diminution in that body's capacity to act'. Massumi $(2002,36)$ asserts that affect is the 'perception of one's own vitality, one's sense of aliveness, of changeability' (italics as in the original). There is an openness to affect that is determined by the body's potential. Hickey-Moody $(2013,80)$ further describes how the variable nature of affect changes the limits of bodies, termed 'the margin of modulation', whether human or non-human, to form part of an assemblage through encounters with 'sounds, lights, smells, the atmospheres of places and people'. An assemblage is a collective of elements, a multiplicity, in the relationships of the constituent parts and in their intersections with other bodies/matter (Deleuze and Guattari 1987). These relationships are central to new materialism 'where things and matter usually perceived as passive and immutable, are instead granted agency’ (Hultman and Lenz Taguchi 2010, 539).

In terms of the medical curriculum, there is scarce mention of affect related to student learning. This is not surprising as medicine is a scientific discourse that relies on evidencebased practices governed by clear accreditation standards with defined, measurable outcomes. For instance, in obstetrics, students need to prove their knowledge on a range of topics and their competence with certain procedures. Signatures from attending midwives and doctors indicate acknowledgement of these skills. Yet the logbook-student-midwife/doctor assemblage appears to be problematic, producing an affective intensity that seems to constrain students, at times inhibiting their desire to respond to unjust practices. A student explained 'nurses don't want to sign, it's very difficult ... it feels like you're sort of held at ransom for signatures' (interview 
2015).

Massumi in conversation with Zournazi refers to affect as a charge that is related to a 'margin of manoeuvrability' that he describes as our positioning of where we might go and what possibilities might arise in each and every situation (Zournazi 2002, 212). In the second section below I delve into curricular matters to elucidate how affect embodies students' engagement with the curriculum.

\section{WHAT MATTERS IN THE OBSTETRICS CURRICULUM?}

A key driver for local curricular reform in medical education is 'to produces doctors who are both excellent and relevant' and who are 'fit-for-service in post-apartheid South Africa' (Seggie 2010, 8). Within the hierarchy of medicine there appears to be limited acknowledgement and accommodation for affect. Scarce attention is given to students' engagement with and through the curriculum, which is complex, uncertain (Barnett 2005), chaotic and at times disturbing, with unwelcome influences shaping their learning (Vivian, Naidu, Keikelame and Irlam 2011). Wear, Zarconi and Namrata (2011) contend that troubling encounters tend to be backgrounded and kept invisible as hidden truths.

For pedagogical engagement on rights violations, Zembylas and Bozalek (2014) propose that a human rights based approach is insufficient, suggesting a move towards affect rather than the rational legalistic mechanisms. To bring change to present practices and values 'which are often rooted in unspoken “emotional” investments in unexamined ideological beliefs' Boler (1999, ix) asserts to the potential of working with and through discomfort.

Although students rarely respond to their own difficult encounters, for example when they witness unjust practices in the clinical workplace, they feel troubled by what they observe and sense the inhibiting nature of the hierarchical power and regulatory structures in medical training (Vivian et al. 2011).

I want to say something but I'm scared, like what do I say? And even if I say something, how's the lecturer going to think of me, how they're going to look at me after I say this (student, focus group 2015).

Such inertia or lack of agency resonates with research by Wear et al. (2011) where American students learnt 'to keep their mouths shut in fear of the consequences of challenging their teachers'. While student support is generally on offer to students, Cvetkovich $(2012,2)$ points out that we need 'to depathologize negative feelings so that they can be seen as a possible resource for political action'.

At the Health Sciences Faculty under study, the students follow the obstetrics curricular 
requirements listed in a course booklet. The different knowledge areas and skills are named in their logbook with the requirement for sign-offs by doctors or midwives in the birthing facilities they visit. This includes the necessity for each student to deliver 15 babies. At the end of the rotation students write up their reflective commentaries then work collaboratively to share a chosen personal narrative in a participatory workshop in the Department of Obstetrics and Gynaecology, facilitated by the author. These narratives have provided alarming evidence over the past five years that students' exposure to abusive, neglectful and disrespectful practices are prevalent, yet remain hidden.

Everybody knew that at some stage sometime this week some woman is going to give birth on the floor. And you're like, - umm, how is that a normal thing? (Student focus group 2015).

Below I draw on Karen Barad's concept of diffraction to explore student learning through their entanglement with different experiences and encounters. This then leads on my visual methodology in which drawings are used.

\section{THINKING GENERATIVELY THROUGH DIFFRACTIVE THEORY}

Rather than critiquing present curricular practices, I take an affirmative, constructive approach that engages with differences to understand what does and can matter in this context of student learning. Barad, a feminist, physicist and philosopher contends that a diffractive analysis is valuable to explore how differences matter. She encourages us to move away from destructive and unhelpful othering and distancing (Barad in Dolphijn and Van der Tuin 2012) and rather 'to make new patterns of understanding-becoming’ (Barad 2014, 187) through constructive and deconstructive insights. This 'involves reading insights through one another in ways that help illuminate differences as they emerge: how different differences get made, what gets excluded, and how those exclusions matter' (Barad 2007, 30).

The concept of diffraction as an analytical tool was initially proposed by feminist Donna Haraway in 1992. Diffraction is explained through an analogy of ocean waves that form variable and integrated new patterns as they intersect with each other. This purposeful strategy engages with difference to pick up the interference patterns and intra-actions that result from a merging together of multiple parts. While interactions are understood as social relationships, intra-actions are dynamic iterative processes mutually constituted through the agency of time, space and matter, where entities, whether they are human or non-human do not pre-exist relationships (Barad 2007).

This relational ontology discards binary, dualistic thinking, such as human/non-human and object/subject. The entangled relationality or mangle as initially described by Pickering 
(1995) is central to understanding how matter matters in material-discursive practices, as I explain in more detail later using drawings. A diffractive perspective seeks out fine details that are initially not visible.

The study discussed in this article uses drawings created in my teaching and inquiry to explore differences-in-the-making. The desiring force was influenced by my personal preference for things visual.

This research project experiments with drawings as a tool for data-in-the-making. It was initially inspired by a local inter-institutional study (Bozalek, Carolissen, Leibowitz, Nicholls, Rohleder and Swartz 2010) in which students' drawings were created in participatory learning activities then later used to illustrate the prevailing racial and institutional tensions. The different perspectives then informed teaching and learning practices towards promoting social justice in education.

Like Holbrook and Pourchier (2014, 754), I found and focused on 'the bits that nudged and pinched [me] from the shadows'. MacLure (2013) contends that research ought to move away from the confines of coding, rather seeking out and explaining data that have an intensity and force on the researcher, creating hotspots that glow. Greene (2013) contends that this type of post-qualitative research, where the researcher is opening up to affective intensities (Ringrose and Renold 2014, 753) is 'dynamic, fluid, indefinite, unfolding'. In the third section of this article I move on to describe how drawings open up affective spaces to understand troubling curricular encounters.

\section{USING VISUAL DATA}

The process of drawing rather than the product of the 'artwork' leads to the generation of new meaning. The force and intensity of the apparatus comprising paper-pastel-hand-studentbecoming elicits valuable insights. What drawings can do rather than what they represent takes a different stance to the 'grammar of images' (Kress and Van Leeuwen 1996) and social semiotics where images are analysed and described in a human-centred and interpretative manner. This can be unhelpful and reductionist as it holds matter at a distance and sets up a binary of subject and object. As Barad $(2007,185)$ points out, 'practices of knowing cannot fully be claimed as human practices, not simply because we use nonhuman elements in our practices but because knowing is a matter of part of the world making itself intelligible to another part. Practices of knowing and being are not isolatable; they are mutually implicated'.

Educational research using drawings as a form of visual communication and data-in-themaking is on the increase (Holbrook and Porchier 2014; Clark 2012; Springgay and Zaliwska 
2015). Drawings/diagrams/images open up opportunities to diffractively explore the entanglement of material-discursive practices and the forces that play out in the unfolding of matter and mattering. This study moves into an entangled space of philosophical inquiry where data-in-the-making facilitate 'more than human' encounters (Springgay and Zaliwska 2015, 136). Manning $(2010,118)$ suggests that this multiplicity of relationships is 'more assemblage than form, more associated milieu than being'.

By reading insights from drawings, students' experiences and theory, through each other, I am using a diffractive analysis that Barad (in Dolphijn and Van der Tuin 2012, 50) suggests can bring 'inventive provocations' that 'are good to think with'. They are respectful, can offer fine detail and considered ethical. What follows is an explanation of how diffractive insights can illuminate affective responses to curricular matters using drawings constructed both in the classroom and in my research project.

Thinking is the conceptual counterpart of the ability to enter modes of relation, to affect and be affected, sustaining qualitative shifts and creative tensions accordingly, which is also the prerogative of art. (Braidotti 2013, 14).

Drawings open up thinking and spaces providing a vital/ity that can diffractively elicit and affirm affective responses by facilitating the flow of affective intensities that act as a potential for new possibilities. In what follows I plug into (Jackson and Mazzei 2013) students’ obstetrics learning experiences and my related research data-in-the-making to diffractively generate new insights into the entanglements of the material-discursive relationships (Barad 2007) emerging from students’ curricular engagement.

Irwin, Ruth, Springgay, Grauer, Xiong and Bickel (2006) explain how the entanglement and performance between art and education is researched through $\mathrm{a} / \mathrm{r} / \mathrm{tography}$, a term used to indicate the multiple and connected identities of the artist, the graphic, the researcher and teacher. A/r/tography investigates relationships that develop in 'an interstitial space, open and vulnerable where meanings and understandings are interrogated and ruptured' (Irwin and Springgay 2008, xx). Simon O'Sullivan $(2006,12)$ suggests that art 'fosters transversal connections and communications ... it allows us to think thought differently'. The drawing activity encourages a pragmatic approach to thinking about experiences, opening up new avenues of thought that will be explored in what follows.

\section{ART-IN-THE-MAKING: OPENING UP THROUGH DRAWINGS}

In the Department of Obstetrics and Gynaecology, our innovative participatory workshops at 
the end of the students' obstetrics rotations began as an experiment to alert students to their roles and responsibilities in terms of human rights education. This later shifted to become more aligned to a socially just pedagogy in which questions were raised about prevailing practices and knowledge constructions (Moje 2007) and space made safe and available to challenge hierarchical structures that limit responses to the present unjust practices. Goodley $(2007,329)$ points out that 'the time is ripe for experimenting with socially just pedagogies towards hope, possibilities and becomings'.

Students are given ownership of the time and the space to share their experiences from their clinical encounters foregrounding human rights issues that have left a mark on them. In each group of approximately 40 medical students, four subgroups present their anecdotal narratives through role-plays, videos, PowerPoint presentations, poetry or other interactive methodologies. The most frequent theme emerging has related to unjust practices witnessed by the students.

In addition to the presentation, sheets of A4 paper and boxes of pastels are handed out during the hour long workshop. Students are asked to freely draw something that stands out for them from their obstetrics learning. The individual images contribute to the emerging conversations and students' affective responses. A photograph of the collection of drawings is later uploaded onto the group's Google Drive folder where the reflective commentaries are also shared together with relevant resources.

Below I describe insights gained through the enactment of the classroom drawings moving on to examples. This leads to drawings as a research tool to supplement interviews, followed by a brief explanation of the limitations arising in this project before concluding.

\section{WHAT EMERGES FROM CLASS DRAWINGS}

Initially the blankness of the paper seemed daunting for some students. Responding to this feedback I later printed a circle on one side of each page. This idea was inspired by three events. Firstly, my own experience in an art class using a circle as a focus to bring a sense of calmness and unity. Secondly, a circular image drawn by a student during the pilot study that sparked my interest. A pencil was used to create a mandala with text rotated and spiralled outwards. A recent study by Potash, Chen and Tsang (2015) indicates how mandala artwork can promote the well-being and professional development of future doctors. Thirdly, the initial drawings by many indicated binary thinking such as good versus bad, for example, sunshine on one side and lightening on the other side of the paper.

What resulted from the presence of circles was impressive. They appear to open up a wider 
spectrum of diffractive responses, a multiplicity in which differences can form new patterns of meaning with and through affect. What emerged were local issues related to student experiences as well as wider challenges associated with the vulnerability of women in labour, such as xenophobia. Moreover, the circles enabled students to reflect on their own positionality as students-becoming-doctors within a struggling health system. The drawings showed details that expressed students' affective responses such as hiding behind tears. They also illuminated the intra-actions and entangled relationships of the facility-student-'woman-in-labour'-midwifedoctor. These involve power and control that influence students' affective responses, such as the dismissal of students during times of grieving, leading to students sensing isolation and helplessness.

The assemblage of paper-pastel-student-facilitator constitutes a complexity of forces that is opening up tensions in student learning. This is an affirmative process with potential to be transformative rather than an evaluative judgement. Workshop feedback demonstrates that students value the peer sharing opportunity in which they sense the events of others. Rather than feeling individually victimized or pathologized, there is a growing concern for shifting response/ability, a desire to act as individuals and collectively. This increase in affective intensity contributes a sensitivity to the different student responses emanating from their eight week learning experience. In the process of drawing, these intensities became even more visible with a few students who used strong and bold colours that resulted from the degrees of pressure exerted in the paper-pastel-hand assemblage. Unlike marker pens, pastels enable these forces to become apparent.

The events expressed through drawings become enactments of a process that makes up the phenomenon of student learning, of 'cutting together-apart', a Baradian term that explains one move in which differences interfere with each other to produce something new. This entanglement of relationships between matter, non-human and human blurs conventional boundaries in time and space. In effect there is 'no absolute boundary between here-now and there-then' (Barad 2014, 168). What students witness in training becomes a part of them in the future.

The drawings appeared to initiate new forces and flows. As students were thinking with and through the act of drawing, material-discursive intra-actions emerged making important connections that often remain invisible to educators. There appeared to be an opening up of flows of intensity through the desire to reveal and to release different emotions, a part of students’ affective responses, 'it opened up my eyes to all the bottled-up emotions I was holding back' ${ }^{1}$ 
In terms of curricular tensions, the drawings in Figures 1 and 2 emerged from students' thinking during a classroom workshop (then explained by the students during a focus group a few weeks later). These drawings provide a small sample of the material-discursive intraactions that constitute students' learning experiences in their journey to becoming doctors.

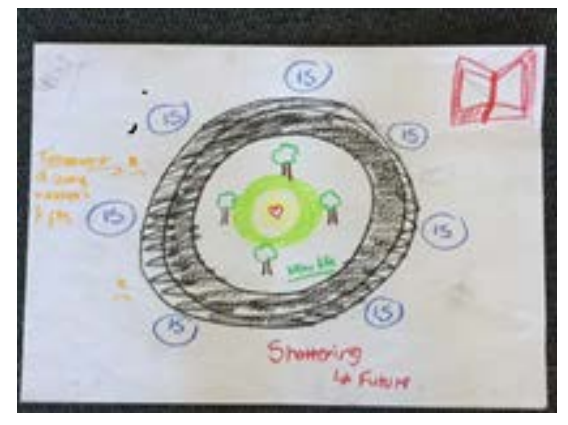

Figure 1: Curricular constraints

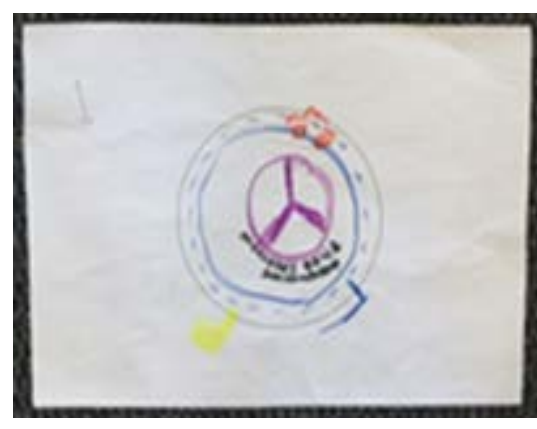

Figure 2: Speeding to catch deliveries

In Figure 1 the student first acknowledged the central joy of birthing. However, this was suppressed by the darker curricular imperative for 15 deliveries and other deliverables of the designed curriculum. The drawing demonstrates how the students' agenda and desire to achieve the required sign-offs (the curricular imperative for accountability and a prerequisite for progress to the next stage in the curriculum) became a noose-like constraint that restricted this student's response to unjust practices - a thread of tension arising from other drawings and workshop conversations.

The drawing in Figure 2 was explained by the student as a Formula 1 racetrack. He was reflecting on his irresponsible and dangerous action when he drove his car 'like a hooligan' ... ‘just to get deliveries done'. He explained that the yellow flag is waved 'when you do something wrong'. His personal success appeared to trump other needs and responsibilities.

Feedback following the classroom workshops indicated how some students appreciated the opportunity to be imaginative, '[it's] awesome to be creative!' Others noted how the coloured pastels and free drawing recalled childhood memories of imaginative playfulness, 'it was fun, especially because some of us have not drawn in years and it is a nice way to express yourself'. Additional comments suggested that the act of drawing was cathartic and refreshing.

Of particular significance was one student's experience. In the classroom the paperpastels-student assemblage felt disempowering. This student explained that she was too angry to draw as a result of a traumatic experience she had witnessed. A vacuum delivery was performed on a 'petrified 15 year old girl' who was given no explanations. The force of the material exacerbated her sense of helplessness and anger. 


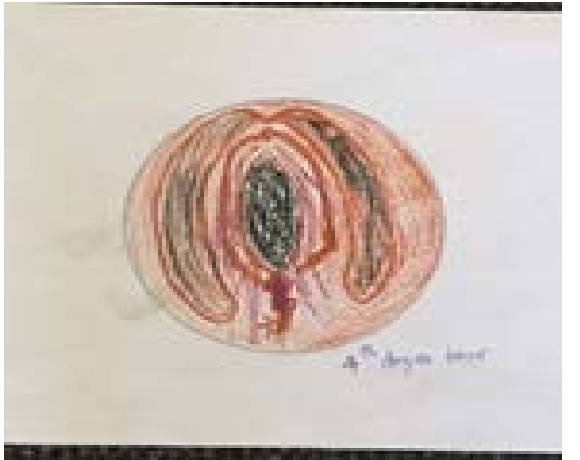

Figure 3: Site of obstetrics violence

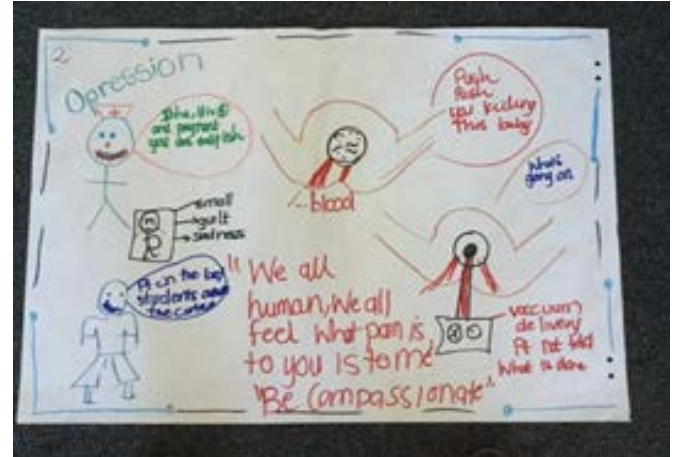

Figure 4: Multiplicity of pain felt by student

Figure 3 was created in class by her kind colleague, assisting her by drawing a perineum with a 4th degree tear - an avoidable complication caused by the limited expertise and apparent lack of compassion of the midwife. Later in our focus group this student confronted a large sheet of A0 paper and, with marked determination and desire, added her sketch - with the events unfolding and becoming visible through the force of the coloured markers which connected with the paper through images and annotations, as indicated in Figure 4. Through email communication and also at a chance meetup in a shopping mall, this student thanked me for the opportunity to share and unload her burden. She wrote 'it's good that there are people like you who actually take time to figure out issues that can be resolved' (email communication September 2015).

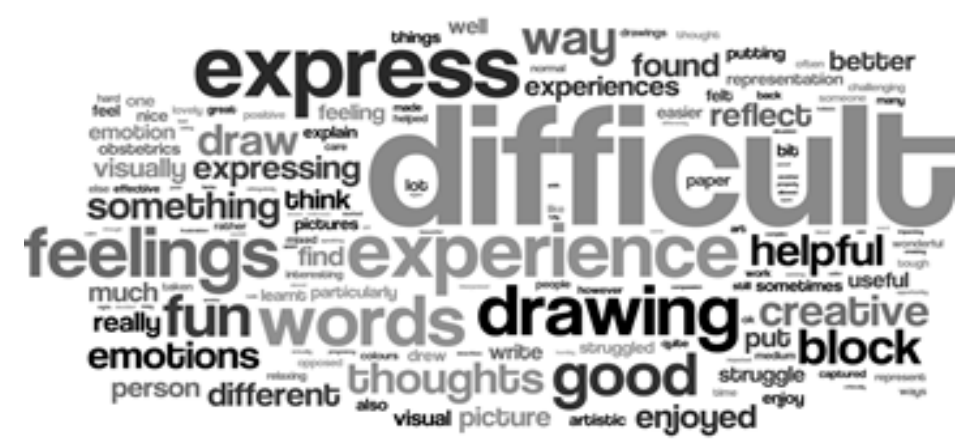

Figure 5: Word cloud representing student feedback on drawing task

General feedback from four student groups in 2015 is indicated on the wordcloud $(n=110)$ in Figure 5 in which the frequency of words is represented visibly through varying font sizes. Students were asked for one word to describe their response to my request for visual representations of their learning during the obstetrics block. Most students indicated how 
difficult it was for them to draw despite the sense of playfulness. One student pointed out that 'it's so broad, you see the different ways that people felt in so many different ways'. Many students felt that the visual medium was challenging for self-expression suggesting their preference for oral or verbal communication - a process that tends to be controlled, deliberate and a conditioned response to marshalling thoughts.

Further insights have emerged through this visual data-in-the-making. The paper and pastels enable some students to express themselves more easily without the limitations imposed by language and text. English is not the first language for a large proportion of our medical undergraduate students. A move away from text as the dominant form of expression is therefore valued by some. For instance, one student said 'I liked how I could express my learning and feeling in another medium other than words'. Another student noted that it was a useful way of thinking critically about the obstetrics experience. The valuable impact of drawings was reinforced by an educator who I interviewed. He remarked on how the drawings could be used in a broader way 'especially when there are language barriers ... [when] they lack the vocabulary ... to express themselves' (interview midwife educator 2015). He requested permission to use the tool for training healthcare providers.

What is apparent is that student drawings can contribute to participatory parity described by Nancy Fraser (2009) as the ability to interact on an equal footing in particular circumstances. Students' voices are being heard, recognised and represented through the image-making. The drawings make visible important insights from students, increasing their affective capacity. Student voices are generally invisible to educators and frequently silenced. Fraser $(2009,16)$ contends that '[o]vercoming injustice means dismantling institutionalized obstacles that prevent some people from participating on a par with others, as full partners in social interaction'.

\section{DRAWINGS FROM EDUCATORS AND STUDENTS IN ONE-ON-ONE INTRA-ACTIONS}

Stender Peterson (2014) suggests that interviews be considered as open-ended apparatuses termed 'intra-views' rather than simply a discussion between two people in an agreed venue. Beyond the human conversation, all matter such as the table and chairs, (and in my situation the paper and pens) form part of the entangled intra-actions. Image-creation aims to 'embrace the entanglement of bodies and language ... includ[ing] the effects of materiality as something that matters' (Stender Peterson 2014, 33). In my research interviews, I asked participants to draw their thoughts and feelings related to our earlier conversations. Each image becomes 'an active material agent' (Stender Peterson 2014, 43), an expanded perspective rather than 
drawings reduced to an end-product of the discourse. A study with surgeons in the United Kingdom who volunteered to draw (postoperatively) about their surgery experiences, showed the value of this pedagogical tool to understand their becoming, and recommended it for medical education (Cristancho and Fenwick 2015).

In my ethics approved research study I interviewed ten educators involved with students' obstetrics learning, as well as two administrative staff members. Departmental encouragement and leadership support has influenced how this project is 'making ripples' promoting positive change to prevailing healthcare practices and student learning. The drawings created by research participants are enactments of the entanglement of the material-discursive relationships elicited through insights and experiences. As mentioned earlier in this article, affect is rarely acknowledged in medical education, yet it seeps into students' learning as they sense differences in power within the strongly established and regulated hierarchy. Issues of loneliness, isolation and neglect have emerged, for instance after a stillbirth the curtains isolate the mother (and the concerned students). Furthermore, there are lasting consequences of sensual memories such as seeing the blood, smelling the placentas and touching 'the untouchable'. Below I explain two drawings that open up students' hidden affective responses to curricular encounters.

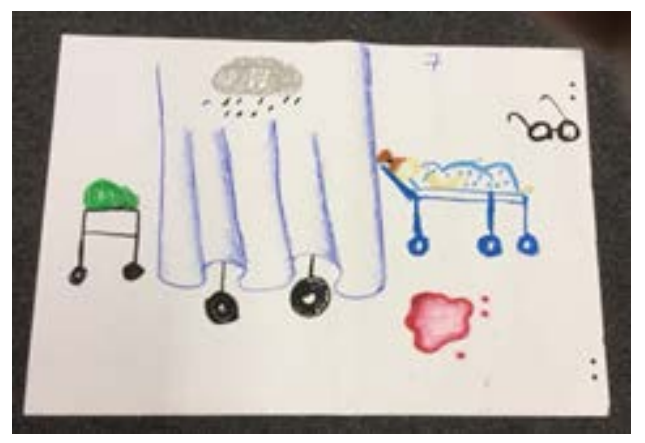

Figure 6: Spectacles of student indicating distancing

In Figure 6 the student began drawing the strong vertical lines indicating the force and intensity of the curtains that acted as a barrier to separate her from a difficult birthing situation. She felt uninformed and isolated as she observed wheels and wagons moving in and out of the space that later became still and silent, leaving a grieving mother alone with her loss. The student was denied the opportunity to be compassionate and caring. 


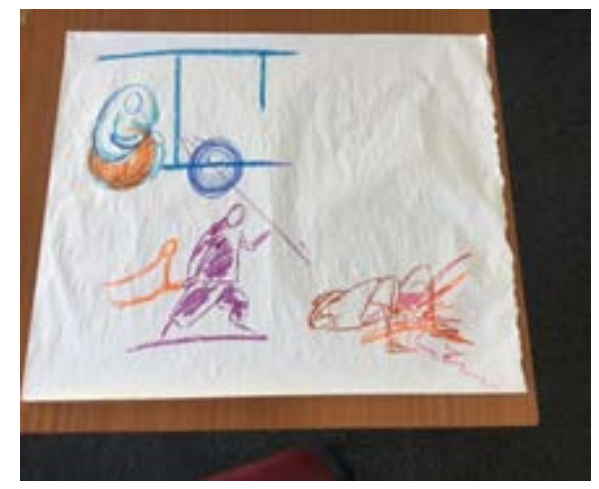

Figure 7: Exercise ball generating comfort compared to pain in forced positioning

Figure 7 shows the drawing created by a final year student in my interview with her as she reflected on her memories from two years earlier. An exercise ball was the first item appearing on the sheet of paper. She explained how these balls ease the pain of women in labour by helping them move into different positions and by a rocking motion. The drawing compared one birthing facility where this student felt positive energy to another where she felt strong negativity associated with great discomfort and disgust. The fresh, brightly painted blue walls that provided an intensity of calmness contrasted with a bed holding down a woman in labour. This static positioning appears to be objectifying and pulling apart the mother-to-be. The student explained 'that's her head down here somewhere, that's her arm closing her eyes'. Blood exploded and pain erupted. This student felt moved by what ought not to happen. She wished she could rather be alongside a caring and confident midwife saying 'I would like to be in the shadow of a good role model'.

Educators, as role models seem to come from different perspectives. Many and varied insights emerged from the inra-actions of paper-pastels-teachers, unfolding in unexpected ways. Drawings were created alongside discussions around symbols of achievement, organizational structuring of the learning block, levels of accountability and responsibility, concern for students' resilience and maturity, as well as the perceived inadequate training of midwives. There was strong recognition with a sense of deep concern about the unjust practices in obstetrics and the impact on students. 


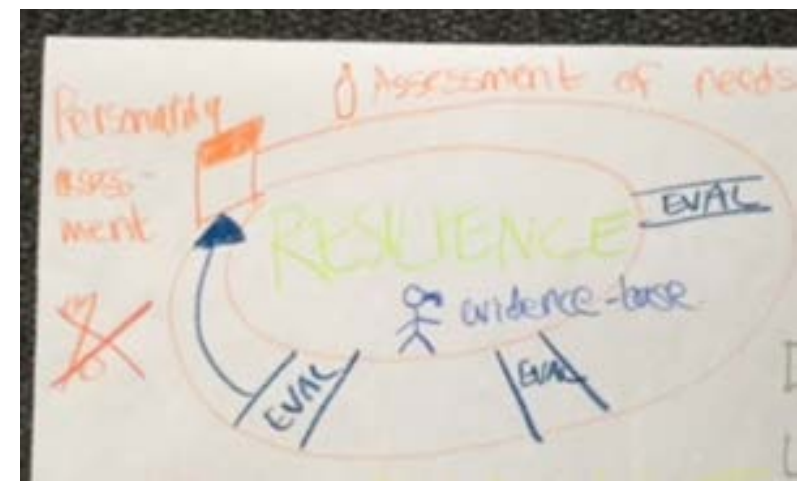

Figure 8: Curriculum as race track

One doctor who drew a blindfolded educator admitted that 'we are stealing opportunities for growth from our students' by not responding to their needs (interview educator 2015). Figure 8 shows how the force of the curriculum appeared as a racetrack similar to the student's drawing in Figure 2, with the main curricular focus on developing student resilience and testing their progress through evidence-based practices.

Figure 9 drawn by a midwife educator illustrates the challenge of a socially just pedagogy in finding a balance between issues of the soul with the provision of information and skills (interview midwife 2015). This questioning is also put forward by Lenz Taguchi and Palmer (2014, 770) who ask '[h] caw we be productive of positive desire in the production of knowing?'.

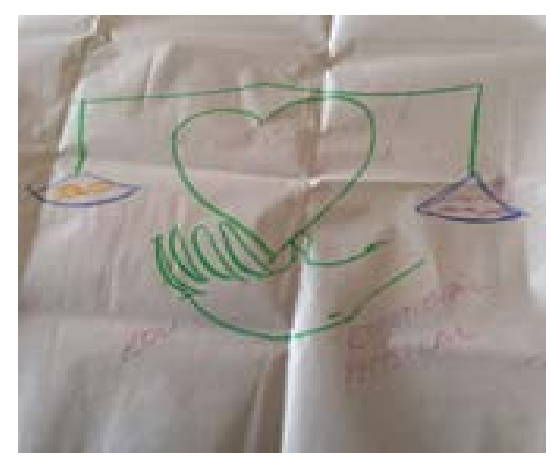

Figure 9: Seeking balance

Discussion of the entangled relationships between learning, research and teaching In these drawing examples, multiple possibilities emerge through the flows of affective intensities, the forces that arise through the material-discursive practice of drawing.

Art is not about representation, concepts or judgement; art is the power to think in terms that are not so much cognitive and intellectual as affective (to do with feeling and sensible experience) 
Colebrook 2002, 12.

The open-endedness of drawings enables the configuration of apparatuses, described as 'dynamic (re)configurings of the world, specific agential practices/intra-actions/performances through which specific exclusionary boundaries are enacted’' (Barad 2007, 134).

These images are generated and constructed by those who create them and are therefore influenced by the entanglement of their thoughts and feelings with time, matter and space. The drawings materialized as intra-activities with enactments that emerged with some surprises. An interviewee said, 'actually what keeps coming back to me is kind of a little weird because it is not what I thought I would draw' (interview midwife 2015).

The image-making enables our attention and voices to be diffracted by shifting the focus away from interpersonal attentiveness towards the paper. Eye contact is lost with the paper and pens holding the intensity of the forces and energies. There is a pulling together-apart. The overlapping conversations can be compared to superimposed waves giving more power and intensity to the discussions, like the 'rolling, pushing and transformation of waves in the sea' (Lenz Taguchi 2012, 270). A different form of communication is taking over with the renewed focus on the paper. The drawings facilitate an affective engagement extending dialogue and a multiplicity of connections as indicated by an educator's comment 'I want to come back to a point that I don’t believe I made in our discussion’ (interview educator 2015). Through the process of drawing there appears to be a rupturing of restraint and perhaps self-censorship to elicit something new.

New important insights emerged through drawings illustrating the release of affective responses that may otherwise have remained hidden or lost. By creating a paper-pen-participant assemblage the flow of affect is facilitated as opposed to a binary construction of object and drawing and subject as research participant. The drawings coming through this study have moved me through new thresholds towards a deeper understanding of student learning that can contribute towards developing a socially just pedagogy. However, challenges are acknowledged related to the process and this study.

\section{LIMITATIONS}

The drawings appear to be opening insights/paths/routes at the intersection of transdisciplinary practices yet this can be undermined by the need for evidence-based practice in scientific discourse. This uncertain methodology is risky. However, Chubbuck and Zembylas (2008, 310) suggest that risks need to be taken as 'the emotional intensity of engaging in socially just teaching is not entirely safe but is full of ambivalence'. 
Images described in this paper were data that glowed for me as the researcher. From another perspective and at another time, other data could offer different meanings and insights. For instance, the drawing of a young girl's perineum held me on the edge as I questioned whether it belonged in this text or ought to be separated out.

This study is based on a teaching and research experience in one educational institution with a single researcher. Further research will be rolled out to include midwives in more birthing facilities.

\section{CONCLUSION}

In this article I explore an in-between space of students' engagement in the obstetrics curriculum. I question how an arts-based mechanism can elicit affect as a pedagogic device towards developing a socially just pedagogy. By revealing unjust practices such as abuse, neglect and disrespect of women in labour witnessed by fourth year medical students in their obstetrics learning, I examine how affect is actually separated out of curricular matters.

Using Barad's diffractive analysis, data that glow are pulled forward to explore the effects and affects of different student experiences. Through art-in-the-making, patterns of meanings became visible from a learning space that tends to remain silent and secretive. I have investigated the intra-activities and interdependencies emerging from the material-discursive practises of classroom teaching and research with unexpected and important insights coming through the connections, interconnections and intra-actions in drawings. A collection of drawings emerging through an iterative process - data-in-the-making, creates a process of 'enabling newness to come into existence; the “more-than” of data' (Springgay and Zaliwska 2015, 137).

The agency of the material has contributed to an improved understanding of student learning often hampered by students' limited opportunity to express their affective responses. Material forces in the curriculum such as the student logbook, a curricular imperative, and the positioning of women in labour in the clinical settings influence the being and becoming of these future doctors. This inquiry into established pedagogical practices in obstetrics is facilitating a shift towards a socially just pedagogy that can open up the precarious entanglement of learning, research and teaching.

While drawings are sometimes viewed as a childlike activity, this undervaluing of the force of the medium is demonstrated as inappropriate. Rather, art-in-the-making that is spontaneous and immediate can contribute an important and valuable affective intensity to promote participatory parity (Fraser 2009), flattening the traditional hierarchy of expertise and 
acting as a tool to contribute to social justice.

We are responsible for the world of which we are a part, not because it is an arbitrary construction of our choosing but because reality is sedimented out of particular practices that we have a role in shaping and through which we are shaped (Barad 2007, 390).

\section{ACKNOWLEDGEMENTS}

This research project is funded by the South African National Research Foundation, Grant no. 86370

\section{NOTE}

1. Student quotes in this article arise from one workshop and related focus group in 2015.

\section{REFERENCES}

Barad, Karen. 2014. Diffracting diffraction: Cutting together-apart. Parallax 20(3): 168-87.

Barad, Karen. 2007. Meeting the universe halfway: Quantum Physics and the entanglement of matter and meaning. Durham and London: Duke University Press.

Barnett, Ronald and Kelly Coate. 2005. Engaging the higher curriculum in higher education. London: SRHE and Open University Press.

Boler, Megan. 2013. Teaching for hope: The ethics of shattering world views. In Discerning critical hope in educational practices, ed. Bozalek, Vivienne, Brenda Liebowitz, Ronelle Carolissen, and Megan Boler. London: Routledge.

Bozalek, Vivienne, Ronelle Carolissen, Brenda Liebowitz, Lindsey Nicholls, Paul Rohleder and Leslie Swartz. 2010. Engaging with difference in higher education: Through collaborative interinstitutional pedagogical practices. South African Journal of Higher Education 24(6): 1021-1035.

Braidotti, Rosi. 2013. The posthuman, Cambridge: Polity Press.

Chadwick, Rachel, Diane Cooper and Jane Harries. 2014. Narratives of distress about birth in South African public maternity settings: A qualitative study. Midwifery 30: 862-858.

Chubbuck, Sharon M. and Michalinos Zembylas. 2008. The emotional ambivalence of socially just teaching: A case study of a novice urban schoolteacher. American Educational Research Journal 45(2): 274-318.

Clark, Vanessa. 2012. Art practice as possible worlds. International Journal of Child, Youth and Family Studies 2 \& 3: 198-213.

Clough, Patricia, ed. 2007. The affective turn: Theorizing the social. Durham and London: Duke University Press.

Colebrook, Claire. 2002. Powers of thinking: Philosophy, art and science. In Understanding Deleuze. Crows Nest, NSW: Allen and Unwin.

Cristancho, Sayra and Tara Fenwick. 2015. Mapping a surgeon's becoming with Deleuze. Medical Humanities 41(2): 128-135. http://www.ncbi.nlm.nih.gov/pubmed/26194103

Cvetkovich, Ann. 2012. Depression: A public feeling. Durham, NC: Duke University Press.

Deleuze, Gilles and Felix Guattari. 1987. A thousand plateaus: Capitalism and schizophrenia. Trans. B. Massumi. Minneapolis, MN: University of Minnesota Press.

Dolphijn, Rick and Iris van der Tuin. 2012. New materialism: Interviews and cartographies. University of Michigan Library: Open Humanities Press. 
Fraser, Nancy. 2009. Scales of justice. Reimagining political space in a globalizing world. New York: Columbia University Press.

Goodley, Dan. 2007. 'Towards socially just pedagogies: Deleuzoguattarian critical disability studies'. International Journal of Inclusive Education 11(3): 317-334.

Greene, Jennifer, C. 2013. On rhizomes, lines of flight, mangles, and other assemblages. International Journal of Qualitative Studies in Education 26(6): 749-758.

Hickey-Moody, Anna and Tara Page, eds. 2015. Arts, pedagogy and cultural resistance: New materialisms.

Holbrook, Teri and Nicole M. Pourchier. 2014. Collage as analysis: Remixing in the crisis of doubt. Qualitative Inquiry 20(6): 754-763.

Hultman, Karin and Lenz Taguchi Hillevi. 2010. Challenging anthropocentric analysis of visual data: a relational materialist methodological approach to educational research. International Journal of Qualitative Studies in Education 23(5): 525-542.

Irwin, Rita L., Beer Ruth, Stephanie Springgay, Kit Grauer, Gu Xiong and Barbara Bickel. 2006. The Rhizomatic Relations of A/r/tography. Studies in Art Education 48(1): 70-88.

Irwin, Rita, L. and Stephanie Springgay 2008. A/r/tography as practice-based research. In Being with A/r/tography, ed. Stephanie Springgay, Rita L. Irwin, Carl Leggo and Peter Gouzouasis. Rotterdam: Sense Publishers.

Jackson, Alicia Y. and Lisa A. Mazzei. 2013. Plugging one text into another: Thinking with theory in qualitative research. Qualitative Inquiry 19(4): 261-271.

Jansen, Jonathan. 2009. Knowledge in the blood: Confronting race and the apartheid past. Cape Town: UCT Press.

Jewkes, Rachel, Naeemah Abrahams and Zodumo Mvo. 1998. Why do nurses abuse patients? Reflections from South African obstetric services. Social Science and Medicine 47(11): 17811795.

Kress, Gunter and Theo van Leeuwen. 1996. Reading images: The grammar of visual design. London. Routledge.

Kruger, LouMari and Christiaan Schoombee. 2010. The other side of caring: Abuse in a South African maternity ward. Journal of Reproductive and Infant Psychology 28(1): 84-101.

Lenz Taguchi, Hillevi. 2012. A diffractive and Deleuzian approach to analysing interview data. Feminist Theory 13(265): 265-281.

Lenz Taguchi, Hillevi and Anne Palmer. 2014. Reading a Deleuzio-Guattarian cartography of young girls' 'school-related' ill-/well-being. Qualitative Inquiry 20(6): 764-771.

MacLure, Maggie. 2013. Classification or wonder? Coding as an analytic practice in qualitative research. In Deleuze and research methodologies, ed. B. Coleman and J. Ringrose, 164-183. Edinburgh, UK: Edinburgh University Press.

Manning, Erin. 2010. Always more than one: The collectivity of a life. Body and society. Sage.

Massumi, Brian. 1987. Notes on the translation and acknowledgments. In A thousand plateaus: Capitalism and schizophrenia, ed. Gilles Deleuze and Felix Guattari. Minneapolis: University of Minnesota Press.

Massumi, Brian. 2002. Parables for the virtual: Movement, affect, sensation. Durham and London: Duke University Press.

Massumi, Brian. 2011. Semblance and event: Activist philosophy and the occurrent arts. MIT Press. Cambridge.

Moje, Elizabeth, B. 2007. Developing socially just subject-matter instruction: A review of the literature on disciplinary literacy teaching. Review of Research in Education 31: 1-44.

O’Sullivan, Simon. 2006. Art encounters Deleuze and Guattari: Thought beyond representation. New York: Palgrave MacMillan. 
Pickering, Andrew. 1995. The mangle of practice: Time, agency, and science. University of Chicago Press.

Potash, Jordan, Judy Yun Chen and Joyce Pui Yang Tsang. 2015. Medical student mandala making for holistic well-being. Medical Humanities. http://mh.bmj.com/content/early/2015/09/04/medhum2015-010717.long

Ringrose, Jessica and Emma Renold. 2014. 'F**k rape!': Exploring affective intensities in a feminist research assemblage. Qualitative Inquiry 20(6): 772-780.

Seggie, Janet, L. 2010. MB ChB curriculum modernisation in South Africa - growing doctors for Africa. African Journal of Health Professions Education 2(1): 8-14.

Springgay, Stephanie and Zophia Zaliwska. 2015. Diagrams and cuts: A materialist approach to research-creation. Cultural Studies $\leftrightarrow$ Critical Methodologies 15(2): 136-154.

Stender, Peterson Kit. 2014. Interviews as intraviews: A hand puppet approach to studying processes of inclusion and exclusion among children in kindergarten. Reconceptualizing Educational Research Methodology 5(1): 32-45.

Vivian, Lauraine, Claudia Naidu, Johannah Keikelame and James Irlam. 2011. Medical students' experiences of professional lapses and patient rights abuses in a South African Health Sciences Faculty. Academic Medicine 86(10): 1282-1287.

Wear, Delese, Joseph Zarconi and Dhillon Namrata. 2011. Teaching fearlessness: A manifesto. Education for Health 24(3): 668-675.

Zembylas, Michalinos. 2006. Witnessing in the classroom: The ethics and politics of affect. Educational Theory 56(3): 305-324.

Zembylas, Michalinos and Vivienne Bozalek. 2014. A critical engagement with the social and political consequences of human rights: The contribution of the affective turn and posthumanism. Acta Academica 4(4): 29-47.

Zournazi, Mary. 2002. Navigating movements -- with Brian Massumi. In Hope: New philosophies for change, 210-243. Australia: Pluto Press. 